Linke/Hau

Internationales Zivilverfahrensrecht 



\section{Internationales \\ Zivilverfahrensrecht}

Begründet von

Prof. Dr. Hartmut Linke †

Richter am Oberlandesgericht

und Honorarprofessor an der

Ruhr-Universität Bochum

Ab der 5. Auflage fortgeführt und neu bearbeitet

von

Prof. Dr. Wolfgang Hau

o. Professor

an der Universität Passau

6. völlig neu bearbeitete

und erweiterte Auflage

2015

\section{ottoschmidt}




\section{Zitierempfehlung:}

Linke/Hau, IZVR, 6. Aufl. 2015, Rz. ...

\section{Bibliografische Information}

der Deutschen Nationalbibliothek

Die Deutsche Nationalbibliothek verzeichnet diese Publikation in der Deutschen Nationalbibliografie; detaillierte bibliografische Daten sind im Internet über http://dnb.d-nb.de abrufbar.

Verlag Dr. Otto Schmidt KG

Gustav-Heinemann-Ufer 58, 50968 Köln

Tel. 02 21/9 37 38-01, Fax 02 21/9 37 38-943

info@otto-schmidt.de

www.otto-schmidt.de

ISBN 978-3-504-65312-5

(C2015 by Verlag Dr. Otto Schmidt KG, Köln

Das Werk einschließlich aller seiner Teile ist urheberrechtlich geschützt. Jede Verwertung, die nicht ausdrücklich vom Urheberrechtsgesetz zugelassen ist, bedarf der vorherigen Zustimmung des Verlages. Das gilt insbesondere für Vervielfältigungen, Bearbeitungen, Übersetzungen, Mikroverfilmungen und die Einspeicherung und Verarbeitung in elektronischen Systemen.

Das verwendete Papier ist aus chlorfrei gebleichten Rohstoffen hergestellt, holz- und säurefrei, alterungsbeständig und umweltfreundlich.

Einbandgestaltung: Jan P. Lichtenford, Mettmann

Satz: WMTP, Birkenau

Druck und Verarbeitung: Betz, Darmstadt

Printed in Germany 